\title{
The impact of knowledge and social influences on adolescents' breast-feeding beliefs and intentions
}

\author{
Vivien Swanson ${ }^{1, *}$, Kevin Power ${ }^{1}$, Binder Kaur ${ }^{1}$, Harden Carter $^{2}$ and Kim Shepherd ${ }^{3}$ \\ ${ }^{1}$ Department of Psychology, University of Stirling, Stirling FK9 4LA, UK: ${ }^{2}$ Lothian Health Board, 148 Pleasance, \\ Edinburgh EH8 9RS, UK: ${ }^{3}$ University of Paisley, Paisley PA1 2BE, UK
}

Submitted 2 March 2005: Accepted 28 June 2005

\begin{abstract}
Objectives: Many health promotion educational interventions assume that increasing knowledge directly influences beliefs, intentions and behaviour, whereas research suggests that knowledge alone is insufficient for behavioural change. Social cognition frameworks such as the Theory of Reasoned Action propose a central role for beliefs and social normative influences. This Scottish study evaluates the role of knowledge and social influences (subjective norms, exposure to breast-feeding, social barriers) on beliefs and future intentions to breast-feed or bottle-feed. Social influences from family and peers are investigated.

Design: A cross-sectional between-subjects observational design was used. A questionnaire was administered to a sample of 229 (46\%) male and 267 (54\%) female adolescents aged $11-18$ years.

Setting: Participants completed questionnaires during lessons at three secondary schools in Central Scotland.

Results: Knowledge about health benefits of breast-feeding was generally poor. Analyses found that perceived social barriers to breast-feeding moderated the relationship between knowledge and beliefs. More knowledge, positive beliefs and supportive subjective norms also predicted future intentions to breast-feed. Parental norms exerted greater influence than peer norms on adolescents' breast-feeding beliefs.

Conclusions: Knowledge and social influences are important predictors of positive breast-feeding beliefs and future intentions to breast-feed in adolescents. This has important implications for breast-feeding health promotion interventions in young people.
\end{abstract}

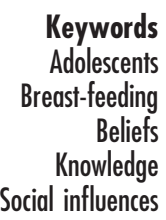

Despite acknowledged health benefits, breast-feeding rates have declined dramatically in developed countries since the early 20 th century ${ }^{1}$. Despite efforts internationally to promote breast-feeding since the 1980s, rates in many countries are less than ideal. Rates of $71 \%$ for England and Wales, 63\% for Scotland and 54\% for Northern Ireland in $2000^{2}$ compare poorly with 98-99\% in Scandinavia, 85-93\% in southern European countries ${ }^{3}$ and $82 \%$ in Australia ${ }^{4}$, and despite attempts to improve breast-feeding rates, increases are generally small ${ }^{5}$. Additionally, definition problems surrounding breastfeeding initiation and maintenance (e.g. does 'breastfeeding' include breast milk from a bottle or 'combined' breast-milk/formula feeding, when is breast-feeding 'considered to be established'?) make accurate comparisons difficult. Most interventions are delivered at the antenatal and postnatal stage and are knowledge-based, although many involve other components such as peer support or support from health professionals. Interventions based on knowledge alone have a relatively poor impact $^{6,7}$ whereas those which are multi-component, accounting for psychosocial and cultural influences, are generally more successful ${ }^{7-9}$.

Many women decide to breast-feed pre-conception ${ }^{9,10}$, suggesting it may be useful to intervene early. Early intervention with adolescents may increase breast-feeding in younger women, who have lower initiation rates. Few studies have examined breast-feeding knowledge, beliefs or attitudes in adolescents*, with only 18 studies published in English between 1980 and 2002 (excluding adolescent mothers). Half were in the USA/Canada, five in the UK and the remainder in developing countries. All measured knowledge, attitudes or intentions but generally lacked theoretical focus, with methodological inadequacies regarding measures and sampling. Only two were based on psychosocial theory ${ }^{11,12}$. Breast-feeding/bottle-feeding

*In addition to hand searches, electronic databases searched included PSYCHINFO, MEDLINE, EMBASE, CINAHL and MIDRS. Timescale for electronic searches was 1980-2002. 
was not clearly defined'. Although men's views are important ${ }^{13-16}, 11$ studies included only girls. Many focused only on breast-feeding, failing to consider the interrelationship between breast-feeding and bottle-feeding attitudes.

Social cognition models, including the Theory of Reasoned Action ${ }^{17}$ (TRA) and the Theory of Planned Behaviour $^{18}$ (TPB), have been applied successfully to breast-feeding ${ }^{19-24}$, but the subjective norm component is relatively weak ${ }^{25-27}$ and uses too narrow a perspective of perceived social influence. Social experience is an important influence of attitudes, and normative influences can be either descriptive (perceptions of what others commonly do) or injunctive (social or moral pressure to perform a behaviour ${ }^{26,28,29}$. Moderation effects of social influence variables in TRA/TPB models are also important, and have been found in recycling intentions ${ }^{30}$ and healthy eating intentions ${ }^{31}$.

\section{Social influences on breast-feeding}

Adolescents are more susceptible than older individuals to normative influences, exhibiting a shift away from parental towards peer group influences. Whether family or peer group influences are more important in relation to health behaviours depends on context ${ }^{32-34}$. Most studies have examined maladaptive health behaviours, such as smoking, which elicit peer support and parental disapproval. However, breast-feeding is an adaptive health behaviour which can receive approval or disapproval from family or peers. Also for younger adolescents, breast-feeding is not immediately focal ${ }^{28}$. Descriptive norms (what others do) may be more important for adolescents who identify strongly with family or peers or have a high level of social conformity, whereas injunctive (social/moral) norms may be affected by individual characteristics such as self-efficacy or rebelliousness.

The social distance (amount of social and emotional contact) of close (family, friends) or distant (strangers) referents may also influence the impact of breast-feeding exposure. Additionally, the social context (private vs. public) is important ${ }^{1,35,36}$. Injunctive (social/moral) beliefs in some cultures mean that breast-feeding in public incurs social disapproval. In one American study, $70 \%$ of middleclass female high school students identified embarrassment as a major barrier to breast-feeding ${ }^{37}$.

Socio-economic status (SES) has a proven influence on breast-feeding although little is said regarding the mechanism for this effect ${ }^{2,38}$. Socialisation processes in some developed Western cultures expose children to images of bottle-feeding more frequently than breastfeeding, and media images promote the sexual image of the breast ${ }^{38}$. The lack of intergenerational experience and exposure to breast-feeding and bottle-feeding has also been shown to influence attitudes, norms and intention in studies in the $\mathrm{USA}^{39}$ and Australia ${ }^{40}$.

\section{Current study}

The current study aims to investigate the impact of social influences on adolescents' knowledge and beliefs and intentions to breast-feed. A TRA framework is used to assess the importance of social influences, including SES, breast-feeding exposure, subjective norm and perceived social barriers to breast-feeding. It also considers social distance, comparing the influence of parents/family and peers. Specific hypotheses are:

1. Social influences (subjective norm, exposure and perceived social barriers) will moderate the relationship between breast-feeding knowledge and beliefs.

2. Similarly, more breast-feeding knowledge, positive social influences and beliefs will enhance adolescents' intentions to breast-feed.

3. A differential effect on beliefs and intentions will be observed according to type of social influence. Descriptive influences (experience/exposure) will have less impact than injunctive influences (subjective norm and perceived social barriers).

4. Referents at greater social distance will exert less influence than close referents.

\section{Method}

\section{Design}

A cross-sectional, between-subjects, observational design was used in a survey of adolescents in Central Scotland.

\section{Participants}

Participants came from three mixed-sex secondary schools - one Roman Catholic and two mixed religion. Schools were selected to include a representative socio-economic mix. Suitable schools were initially identified by Education Authorities and permission obtained via the headteacher. Since negative breast-feeding beliefs are highly correlated with social disadvantage ${ }^{41,42}$, one school from an area of high social disadvantage was included. Pupils were in three age bands: 11-13 years (Years S1 and S2), 14-15 years (Years S3 and S4) and 16-18 years (Year S5).

Ethical approval was obtained from the University Psychology Departmental Ethics Committee. Class groups were selected according to school timetables and availability, and letters were sent to parents to obtain consent. Four (S1/S2) pupils from one school were excluded since parents withheld consent. Questionnaires were administered in a range of subject classes. From 506 participants, six questionnaires were not fully completed, thus 500 questionnaires were analysed.

\section{Procedure}

A brief verbal introduction to the topic of infant feeding was provided by a member of the research team in a standard format before participants completed the 
questionnaire. This explained that in the first weeks of life babies are fed either human breast milk or infant formula via a bottle. The difference between breast-feeding, bottlefeeding and combined feeding was explained, examples presented and questions answered. Additionally, a short written introduction was provided at the beginning of the questionnaire, stating that it was looking at how newborn babies are fed before they start eating solid food. World Health Organization definitions ${ }^{43}$ were provided as follows:

- Breast-feeding - baby gets milk from the mother's breast.

- Combined feeding - baby gets both breast milk from the mother and formula milk in a bottle.

- Bottle-feeding - baby gets formula/powdered milk from a bottle.

Participants were asked to read the questions carefully, asking the teacher or researcher if they did not understand any question, and to read over the questionnaire to check for missing answers.

\section{Instruments}

A 69-item self-report questionnaire was developed specifically for this study. Where possible, items were based on previous studies which had successfully used the TRA/TPB approach ${ }^{17}$. Items were reviewed for face validity by all members of the study team, which included academic psychologists, a public health consultant and a community nursing specialist. Prior to administration the questionnaire was piloted informally with a small convenience sample of $(n=5)$ adolescents to ensure readability and ease of understanding.

\section{Demographic variables}

Participants provided gender, age and year group information. Post codes (or street names) provided SES using the 'DEPCAT' (deprivation categories) method ${ }^{44}$, generating six categories that enabled allocation of participants to 'high', 'middle' and 'low' SES.
Own feeding experience

Participants were asked whether they had been breast-fed, bottle-fed or 'combined-fed', or 'didn't know'. Although some individuals may have been told how they were fed, others may have made an assumption because of prevailing attitudes within their family. This is therefore a 'subjective' rather than 'objective' measure.

\section{Intentions}

Participants were asked how they intended to feed their baby if they became a parent in the future. Four mutually exclusive response categories were available - breast-fed, bottle-fed, 'combined-fed' and don't know.

\section{Knowledge of breast-feeding and bottle-feeding}

This included seven statements assessing knowledge of health benefits of breast-feeding and bottle-feeding. Items were taken from a review of knowledge items from other studies, screening out those deemed inapplicable to adolescents, and were reviewed by the study team. We specifically aimed to avoid bias towards breast-feeding by including questions based on 'bottle-feeding'. Items (listed in Table 1) were scored with 'true', 'false' and 'don't know' response options. For every correct answer participants scored 1 , incorrect or don't know responses scored 0. Items were tallied and scored $0-7$. Reliability analysis gave a Cronbach's $\alpha$ of 0.66 .

\section{Breast-feeding beliefs}

Beliefs can be categorised as cognitive, affective and behavioural $^{45}$. A scale was constructed to measure breastfeeding beliefs including these components, using questions derived from studies of mothers and partners ${ }^{4,19}$. Items lacking relevance for adolescents were excluded and items applicable to adolescents added (e.g. 'breast-feeding is rude') ${ }^{35}$. The nine items reflected cognitive beliefs about breast-feeding characteristics and values (e.g. 'breast-feeding limits the mother's social life'); affective beliefs about emotional responses (e.g. 'breastfeeding is embarrassing for the mother'); and behavioural beliefs referring to experience (e.g. 'breast-feeding can be uncomfortable for the mother'). A 7-point Likert scale rated responses from 1 ('strongly disagree') to 7 ('strongly

Table 1 Adolescents' health knowledge for breast-feeding and bottle-feeding

\begin{tabular}{|c|c|c|c|}
\hline Item & True, $n(\%)$ & False, $n(\%)$ & $\begin{array}{c}\text { Don't } \\
\text { know, } n(\%)\end{array}$ \\
\hline Bottle-feeding is just as healthy for the baby as breast-feeding (F) & $148(29.7)$ & $200(40.1)$ & $151(30.3)$ \\
\hline Breast-feeding helps to prevent allergies and infections in the baby $(T)$ & $180(36.1)$ & $67(13.4)$ & $252(50.5)$ \\
\hline Formula milk (bottle-feeding) provides the same vitamins and nutrients found in breast milk $(F)$ & $106(21.0)$ & $193(38.7)$ & $200(40.1)$ \\
\hline Breast-feeding is good for the mother's health $(T)$ & $98(19.7)$ & $51(10.2)$ & $349(70.1)$ \\
\hline Bottle-feeding provides protection against infection $(F)$ & $91(18.3)$ & $162(32.5)$ & $245(49.2)$ \\
\hline Babies need to be breast-fed for at least the first four months of life for greatest health benefits* $(T)$ & $166(33.3)$ & $123(24.7)$ & $209(48.2)$ \\
\hline It is not healthy to bottle-feed a baby for more than the first year of life $(T)$ & $113(22.7)$ & $145(29.1)$ & $240(48.2)$ \\
\hline
\end{tabular}

Numbers vary slightly due to missing data. $\mathrm{T}-$ true; $\mathrm{F}-$ false.

* These data were collected before publication of World Health Organization and other directives recommending 6 months of exclusive breast-feeding. 
agree'), and items were totalled. Some items were reversescored to reflect positive agreement with breast-feeding. Reliability analysis gave Cronbach's $\alpha$ of 0.73 .

\section{Social influences}

Descriptive norms: perceived exposure to breast-feeding. Participants were asked whether they had seen a baby being breast-fed by referents at increasing levels of social distance (family member, friend of family, stranger, someone on TV). Questions were scored 'yes' or 'no'. Participants replying 'yes' were asked to select a category representing the number of times they had seen that person feeding: $1-2$ (scored 1), 3-10 (scored 2$)$ and $>10$ (scored 3). Totals provided an index of overall exposure. Exposure to bottle-feeding was measured similarly. Participants were also asked if they had bottle-fed a baby themselves.

Injunctive normative influences. Injunctive norms were measured using subjective norm measured as per the TRA and assessing perceived social barriers.

1. Subjective norm: Subjective norm consisted of two items representing normative beliefs and motivation to comply, asking participants: (i) if they had a baby in the future, whether people important to them would advise them to breast-feed and (ii) how far they would be likely to follow this advice. A 7-point Likert scale was used, giving a score from 1 to 7 . In accordance with the TRA/TPB model ${ }^{46}$, normative belief and motivation scores were multiplied to give a weighted subjective norm for analysis.

2. Perceived social barriers: A second injunctive measure was included to give a detailed perspective of normative influences in social contexts. Seven scenarios measured perceived social barriers to breastfeeding in different environments ${ }^{47}$ and included referents at increasing levels of social distance, i.e. the participants' mother, family friend and strangers breast-feeding in public or private, and seeing someone breast-feed on TV. Participants were asked whether they agree or disagree that the person should breast-feed in each environment. The items were scored on a 5-point Likert scale from 1 ('strongly disagree') to 5 ('strongly agree') and a total calculated. The scale was scored in a positive direction where higher scores represent fewer barriers. Overall reliability was $\alpha=0.86$. To investigate social distance, three subscales were created representing close family members (two items; $\alpha=0.63$ ), friends (two items; $\alpha=0.63$ ) and 'people you do not know' (two items; $\alpha=0.73)$.

\section{Statistical analyses}

Items were checked for linearity and normality. Regression variables (excluding demographic variables) were mean-centred to reduce effects of collinearity ${ }^{48}$. The impact of knowledge and social influences on beliefs and intention was investigated using hierarchical linear and logistic regression, respectively. The moderating effect of knowledge on social influences was investigated by creating the product term of two centred independent variables. Demographic variables were entered as a first block and knowledge as a second block, assuming these would theoretically underpin beliefs and social influences. SES was included in initial regressions but was not a significant predictor, so was subsequently excluded. Beliefs were entered next, followed by social influences and finally interactions. Simple univariate relationships were investigated using $t$-tests, one-way analysis of variance, Pearson correlations and chi-square tests. Analyses were performed using SPSS for Windows version 10.0 (SPSS Inc., Chicago, IL, USA, 1989).

\section{Results}

Respondents were broadly balanced for gender (229, $45.8 \%$ male; $267,53.4 \%$ female) and age group (S1/S2: 177 , $35.4 \%$; S3/S4: 176, 35.2\%; S5: 144, 28.8\%). The age range was 11-18 years. There were fewer participants in the high SES group $(37,7.4 \%)$ in comparison with middle $(279,55.8 \%)$ and low $(162,32.4 \%)$ categories.

\section{Own feeding experience and intentions}

Around 30\% $(n=146)$ of pupils reported having been breast-fed and a slightly higher proportion (196, 40\%) bottle-fed. Only 26 (5\%) were 'combined-fed' and 130 (26\%) did not know how they had been fed, including a higher proportion of boys (88, 38\%) than girls (42, 16\%). There were no differences between SES groups having been breast-fed, bottle-fed or 'combined-fed' ( $\chi^{2}=7.4$, $\mathrm{df}=4$, not significant).

The sample divided into approximately equal groups regarding future feeding intentions. Overall, 147 (29\%) participants intended to breast-feed, 129 (26\%) to bottlefeed, 120 (24\%) to 'combined-feed' and 102 (20\%) did not know. More boys (80, 35\%) than girls $(65,24 \%)$ expressed a preference for breast-feeding, and more girls (90, 34\%) than boys $(38,17 \%)$ opted to bottle-feed $\left(\chi^{2}=20.6\right.$, $\mathrm{df}=3, \quad P<0.001)$. Future intentions varied by age $\left(\chi^{2}=22.435\right.$, df $\left.=6, P<0.001\right)$. More 16-18-year-olds intended to breast-feed $(51,35 \%)$, whereas more 11-13year-olds $(53,30 \%)$ and 14-15-year-olds (40, 23\%) intended to bottle-feed. There were no SES differences in intentions.

Exploratory analysis compared attitudes of pupils who intended to 'combined-feed' with those who intended to breast-feed or bottle-feed. Significant differences emerged between combined feeding and bottle-feeding, but not between combined feeding and breast-feeding. We therefore classified 'combined-feeders' and breast-feeders as one group for subsequent analysis. 
Future intentions were related to own feeding experience. Those who intended to breast-feed were more likely to have been breast-fed $(122,68 \%)$ than bottlefed $(62,32 \%)\left(\chi^{2}=89.9\right.$, df $\left.=1, P<0.001\right)$. Participants who had been breast-fed reported more positive attitudes to breast-feeding (mean 48.3, standard deviation (SD) 7.0) than those who had been bottle-fed (mean 43.8, SD 8.0) $(t(355)=5.6, P<0.001)$. Similarly, those intending to breast-feed reported more positive attitudes (mean 47.8, SD 6.6) than those who did not (mean 42.4, SD 7.7) $(t(478)=8.4, P<0.001)$.

\section{Knowledge}

Overall knowledge of health benefits of breast-feeding and bottle-feeding was generally poor. Mean score for the seven items was 202 out of a possible 7 . Table 1 shows the number (\%) of true, false and 'don't know' scores for each item. Misconceptions about bottle-feeding were common, as was lack of knowledge about the health benefits of breast-feeding. Intended breast-feeders had better overall knowledge scores (mean 2.8, SD 1.8) than others (mean 1.7, SD 1.4) $(t(492)=7.4, P<0.001)$.

Table 2 shows means and correlations between study variables. There was no gender difference in knowledge, beliefs or subjective norms. However, girls reported more exposure $(t(472)=4.3, P<0.001)$ and fewer social barriers to breast-feeding than boys $(t(480)=2.0$, $P<0.05)$. Better knowledge was negatively related to SES and positively associated with age, more positive beliefs and subjective norm, more exposure and fewer social barriers to breast-feeding. There were significant positive but moderate correlations between aspects of social influence.

\section{Predicting breast-feeding beliefs}

To test the first hypothesis, hierarchical regression investigated the impact of social influence and knowledge on breast-feeding beliefs (Table 3). The model including interactions predicted 30\% of variance in beliefs. Each block added significantly. Age was the only significant demographic predictor, and knowledge was a highly significant predictor. In relation to the third hypothesis, only one social influence variable - perceived social barriers - predicted beliefs. The interaction between knowledge and social barriers was also significant, suggesting a moderating effect.

This relationship was investigated by plotting the knowledge $\times$ barriers interaction using simple slope analysis $^{48}$, as shown in Fig. 1. Regression lines were examined at $1 \mathrm{SD}$ above and below the mean. When there were few perceived barriers to breast-feeding (higher barrier scores), both high and low levels of knowledge were related to more positive beliefs. However, when there were more social barriers to breast-feeding (lower barrier scores), individuals with poor knowledge had more negative beliefs than those with better knowledge.

\section{Predicting future feeding intentions}

To test the second hypothesis, knowledge, social influences and beliefs were investigated in relation to intentions (Table 4). Using the same model, variables were entered in blocks, with two-way interaction terms as a fourth block, and three-way interaction terms for knowledge, social influence variables and beliefs entered as a final block.

The model without interaction terms was significantly different from the beginning block with $72.1 \%$ of cases correctly classified overall, $74 \%$ of intended breast-feeders and $70 \%$ of others. Adding interactions did not improve this model significantly, and no interaction terms were significant. When beliefs were added, the significant effect of social barriers was lost, and exposure and subjective norm both reached significance. Odds ratios (exp $B$ ) showed that adolescents with more knowledge were 1.5 times more likely to intend to breast-feed, and those with more positive subjective norm were 1.7 times more likely to intend to breast-feed.

\section{Social influences}

Only 47 (9\%) participants reported no exposure to breastfeeding and two reported no exposure to bottle-feeding. More participants had seen breast-feeding on TV (71\%) than had seen a family member (35\%), family friend (27\%) or stranger breast-feeding (37\%) (Table 5). In relation to

Table 2 Means and Pearson correlations for study variables: age, knowledge, breast-feeding beliefs and social influence variables for $n=500$ adolescents

\begin{tabular}{|c|c|c|c|c|c|c|c|c|c|c|}
\hline & Measure & Mean & SD & 1 & 2 & 3 & 4 & 5 & 6 & 7 \\
\hline 2 & Knowledge & 2.2 & 1.7 & $0.16^{\star \star}$ & - & & & & & \\
\hline & Social influences & & & & & & & & & \\
\hline 4 & SES & 4.2 & 1.1 & $-0.17^{\star \star}$ & $-0.12^{*}$ & -0.01 & - & & & \\
\hline 7 & Social barriers & 19.8 & 11.5 & $0.13^{\star *}$ & $0.26^{\star \star \star}$ & $0.18^{\star \star \star}$ & 0.02 & $0.17^{* \star *}$ & $0.13^{\star *}$ & - \\
\hline
\end{tabular}

SD - standard deviation; SES - socio-economic status.

${ }^{\star}, P<0.05 ;{ }^{* \star}, P<0.01 ;{ }^{* \star}, P<0.001$. 
Table 3 Linear regression analysis predicting adolescents' breast-feeding beliefs

\begin{tabular}{|c|c|c|c|c|}
\hline Variables & $R$ & Adjusted $R^{2}$ & (df), $F$ change & $\beta \dagger$ \\
\hline Block 1 & 0.25 & 0.06 & $(3,426), 9.50^{\star \star \star}$ & \\
\hline Age & & & & $0.25^{\star \star \star}$ \\
\hline Gender & & & & 0.03 \\
\hline SES & & & & 0.02 \\
\hline Block 2 & 0.35 & 0.12 & $(1,425), 29.15^{\star \star \star}$ & \\
\hline Knowledge & & & & $0.25^{\star \star \star}$ \\
\hline Block 3 & 0.55 & 0.29 & $(3,422), 35.13^{\star \star \star}$ & \\
\hline Exposure & & & & 0.03 \\
\hline Subjective norm & & & & $0.12^{\star}$ \\
\hline Social barriers & & & & $0.39^{\star * \star}$ \\
\hline Block 4 & 0.56 & 0.3 & $(3,419), 2.65^{\star}$ & \\
\hline Knowledge $\times$ exposure & & & & -0.02 \\
\hline Knowledge $\times$ subjective norm & & & & 0.04 \\
\hline Knowledge $\times$ social barriers & & & & $-0.13^{\star \star}$ \\
\hline
\end{tabular}

SES - socio-economic status.

${ }^{\star}, P<0.05 ;{ }^{\star *}, P<0.01 ;{ }^{* \star}, P<0.001$.

$\dagger$ Beta values reported are at entry.

the fourth hypothesis, participants reported more exposure from close (family) than distal referents. Exposure to bottle-feeding was much more common than breast-feeding. The vast majority $(423,86 \%)$ had seen a close referent or someone on TV (443, 89\%) bottlefeeding. Most (74\%) had seen strangers bottle-feeding and $74 \%$ had bottle-fed a baby themselves.

Participants perceived fewer barriers to seeing a family member breast-feeding than friends or strangers. However, context was important. Participants recorded more approval for close referents breast-feeding in private, and distal referents received more approval for breast-feeding in public.

To test the fourth hypothesis, comparing the influence of different referents, breast-feeding beliefs were regressed onto 'exposure' items for family, friends and strangers, and onto social barriers combining 'public' and 'private'

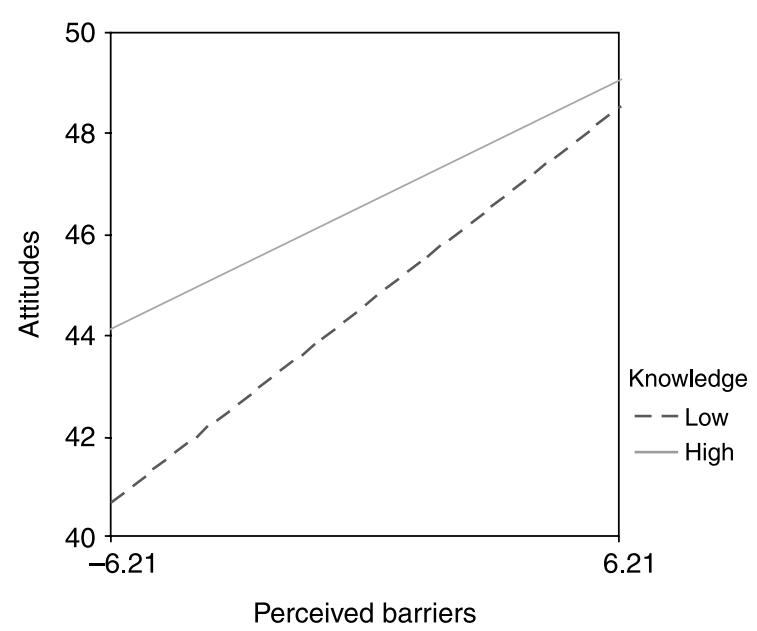

Fig. 1 Simple regression slopes showing regression of attitudes on perceived social barriers for low $(-1 S D)$ and high (+1SD) levels of knowledge (SD, standard deviation) contexts for family, friends and strangers. Since there was a significant age gradient in both exposure and perceived social barriers to breast-feeding, age was controlled.

Age and exposure to breast-feeding predicted $15 \%$ of the variance in beliefs $\left(F\left(3,45^{*}\right)=3.30, P<0.05\right)$. Age $(\beta=0.31, P<0.05)$ and exposure to family referents $(\beta=0.40, \quad P<0.01) \quad$ were significant individual predictors.

Age and perceived social barriers predicted $21 \%$ of the variance in beliefs $(F(3,460)=44.27, P<0.001)$. Age $(\beta=0.24, \quad P<0.001)$ and family referents $(\beta=0.29$, $P<0.001)$ were significant individual predictors. Values for friends $(\beta=0.13, P=0.05)$ and strangers $(\beta=0.11$, $P=0.06)$ approached significance.

\section{Discussion}

Promoting positive beliefs about breast-feeding in adolescents is an important precursor of future breast-feeding. This Scottish study showed that both knowledge of the health benefits of breast-feeding and perceived social influences were important individual predictors of positive breastfeeding beliefs, and also identified an interaction effect.

Knowledge was poor overall. In particular, few adolescents knew that breast-feeding was good for the mother's health. It is difficult to compare knowledge from our sample with other groups since measurement and definition of 'knowledge' vary considerably between studies internationally, and knowledge is often conflated with beliefs or attitudes. It is difficult to devise objective indicators of knowledge that are appropriate for adolescents, and we anticipated obtaining a 'floor' effect if we had included more 'physiological' items (such as

*Degrees of freedom were much reduced in this analysis, since few participants recorded exposure from social referents in all categories. 
Table 4 Logistic regression analysis predicting intention to breast-feed

\begin{tabular}{lccccc}
\hline Variables & Model $\chi^{2}$ & $\%$ of cases predicted & Wald & Exp B十 & $95 \% \mathrm{Cl}$ for exp B \\
\hline Block 1 & $9.3^{* *}$ & 57.8 & & & \\
Age & & & $5.44^{*}$ & 1.12 & $1.04-1.33$ \\
Gender & & & 0.29 & 1.42 & $0.97-2.09$ \\
SES & & & & 0.96 & $0.81-1.15$ \\
Block 2 & $56.76^{* * *}$ & 65.1 & & & \\
Knowledge & & & $40.18^{\star * *}$ & 1.55 & $1.35-1.77$ \\
Block 3 & $148.06^{\star * *}$ & 72.1 & & & \\
Beliefs & & & $18.89^{* * *}$ & 1.09 & $1.05-1.13$ \\
Exposure & & & $5.36^{*}$ & 1.16 & $1.02-1.31$ \\
Social barriers & & & 0.24 & 1.01 & $0.97-1.06$ \\
Subjective norm & & & $33.41^{* * *}$ & 1.72 & $1.43-2.07$ \\
\hline
\end{tabular}

$\mathrm{Cl}$ - confidence interval; SES - socio-economic status.

${ }^{*}, P<0.05 ;{ }^{* *}, P<0.01 ;{ }^{* * \star}, P<0.001$.

$\dagger \operatorname{Exp} B$ values reported are at entry.

Table 5 Exposure to breast-feeding and perceived social barriers to breast-feeding for referents at different levels of social distance

\begin{tabular}{|c|c|c|c|}
\hline & \multicolumn{2}{|c|}{ Ever exposed } & \multirow[b]{2}{*}{ Frequency of exposure, mean (SD) $\dagger$} \\
\hline & Yes, $n(\%)$ & No, $n(\%)$ & \\
\hline \multicolumn{4}{|l|}{ Exposure to breast-feeding } \\
\hline Close family member & $173(34.6)$ & $326(65.2)$ & $1.8(0.79)$ \\
\hline Friend/friend of family & $134(26.8)$ & $360(72.0)$ & $1.6(0.67)$ \\
\hline Stranger & $186(37.2)$ & $311(62.2)$ & $1.3(0.51)$ \\
\hline Someone on TV & 357 (71.4) & $140(28.0)$ & $1.4(0.56)$ \\
\hline Perceived social barriersł & & & Mean score \\
\hline Close family member (private) & & & $3.66(1.3)$ \\
\hline Close family member (public) & & & $2.22(1.2)$ \\
\hline Friend/friend of family (private) & & & $2.32(1.2)$ \\
\hline Friend/friend of family (public) & & & $2.87(1.2)$ \\
\hline Stranger (private) & & & $2.67(1.3)$ \\
\hline Stranger (public) & & & $2.91(1.2)$ \\
\hline Someone on TV & & & $3.66(0.95)$ \\
\hline
\end{tabular}

SD - standard deviation.

†Range 1-3.

†Higher scores represent fewer perceived social barriers.

protection against breast cancer for the mother or constituents of breast milk). We were also concerned to avoid bias towards breast feeding in this study and attempted to balance breast-feeding and bottle-feeding knowledge in constructing the measure. Some of the items in our knowledge measure may reflect beliefs and have been influenced by the participants' own experience of breast-feeding. Standardisation of knowledge items would be useful for future research and could be a useful intervention tool for health educators.

The impact of knowledge on beliefs was moderated by social influences, particularly perceived social barriers, suggesting it is insufficient to focus only on knowledge in breast-feeding promotion. Adolescents with more social barriers to breast-feeding, and less knowledge, had more negative beliefs overall. Previous studies have also identified the social context of breast-feeding as an important influence in adolescents $s^{1,15,35-37}$. The idea that breast-feeding involves exposure of the breast in public is clearly uncomfortable to many, and breasts are seen as only sexual objects in many cultures ${ }^{38}$. The acceptability of breast-feeding in public is an important issue for supporting breast-feeding continuation, and is currently the focus of legislation in Scotland ${ }^{49}$. Interestingly, participants differentiated between social referents in different contexts - being most concerned about a family member breast-feeding in public.

Beliefs, knowledge and social influences also predicted adolescents' future breast-feeding intentions. As in previous studies, descriptive norms (breast-feeding exposure) exerted a significant, although smaller impact on beliefs and intentions than injunctive norms ${ }^{31,50}$. However, whereas perceived social barriers influenced beliefs, subjective norm predicted intentions. These different types of injunctive social influence represent different individual cognitions about breast-feeding. 
Perceived social barriers reflect the public context of breast-feeding, and link to individual moral and emotionally influenced beliefs about embarrassment, the sexuality of the breast and beliefs about contact with breast milk as a bodily fluid ${ }^{36}$. The subjective norm concept is a more general reflection of perceived social pressure on adolescents to breast-feed and their motivation to comply with family and peer influences.

Many studies have investigated the impact of social influences, particularly peer and parental influences, on health behaviour. One ${ }^{34}$ suggested that family socialisation/parental influences on health beliefs and behaviours are most important whilst adolescents are living at home. Our study supports this view in relation to breast-feeding, although influences from peers and the media were also influential.

If family socialisation and modelling are important mechanisms for encouraging positive attitudes, then it is important that adolescents should be exposed to positive images of breast-feeding in the family. The proportion of adolescents who reported being exclusively/'combined-fed' themselves (54\%) was close to breastfeeding rates for Scotland in the late $1980 \mathrm{~s}^{41}$, suggesting that their perceptions were relatively accurate. Own feeding experience was closely related to future breastfeeding/bottle-feeding intentions.

Participants reported significantly more exposure to bottle-feeding than breast-feeding, suggesting that there is a long way to go before breast-feeding becomes the cultural norm in some developed countries. The role of the media may be particularly important. A recent study found a direct relationship between media exposure to cigarette smoking and increased smoking in adolescents ${ }^{51}$. Whilst it is encouraging that over $70 \%$ of our participants had seen 'someone on TV' breast-feeding, most had only witnessed this once or twice, whereas bottle-feeding on TV appeared more common. Increasing media exposure to breast-feeding, particularly in TV programmes watched by adolescents, may help improve breast-feeding rates.

Research has consistently identified socio-economic differences in breast-feeding attitudes, intentions and behaviour $^{2,4,41}$. We found fewer SES differences than expected, perhaps because young people's health behaviour and lifestyles increasingly cut across social class boundaries ${ }^{52}$. There were also interesting gender differences. Boys reported less exposure to breast-feeding, but were nevertheless more likely to intend their own baby to be breast-fed than girls. This may reflect greater realism in girls regarding breast-feeding practicalities and impact on their body, body image and lifestyle, and has important implications for encouraging more young women to breast-feed in future.

\section{Study limitations}

Although results were robust, some issues arise regarding study design. Although the research adopted a TRA/TPB approach, it did not fully operationalise the model. Other potentially important social influences were not included, particularly self/group identity ${ }^{30}$. The cross-sectional nature of the research can be criticised. Social cognitions may change over time with experience ${ }^{6}$, and a longitudinal investigation or intervention would establish causality for the impact of knowledge, beliefs and norms on adolescents' behaviour. Standardised, reliable, valid measures of psychosocial aspects of breast-feeding, including knowledge, would also improve the quality of future studies.

\section{Conclusions}

This study highlights the importance of social influences and knowledge in breast-feeding education. Breastfeeding beliefs, attitudes and intentions can be influenced during adolescence, and school-based health promotion efforts would be valuable. More exposure to positive images of breast-feeding in families and the media would ensure it becomes the 'normal' way of feeding babies in future generations.

\section{Acknowledgement}

The research described in this paper was funded by a grant from the Scottish Executive Chief Scientist Office, Ref $\mathrm{CZG} / 3 / 2 / 18$.

\section{References}

1 Ellis DJ. Secondary school students' attitudes and beliefs about breastfeeding. Journal of School Health 1983; 53(10): $600-4$.

2 Hamlyn B, Brooker S, Oleinikova K, Wands S. Infant Feeding Survey 2000. London: Department of Health, 2002.

3 World Health Organization (WHO). Health Statistics 2003. Geneva: WHO, 2003.

4 Forster D, McLachlan H, Lumley F, Beanland C, Waldenstrom $\mathrm{U}$, Amir L. Two mid-pregnancy interventions to increase the initiation and duration of breastfeeding: a randomized controlled trial. Birth 2004; 31(3): 176-82.

5 Tappin D, Mackenzie JM, Brown AJ, Girdwood RWA, Britten $\mathrm{J}$, Broadfoot $\mathrm{M}$, et al. Breastfeeding rates are increasing in Scotland. Health Bulletin 2001; 59(2): 102-8.

6 Pobocik RS, Benavente JC, Schwab AC, Boudreau N, Morris $\mathrm{CH}$, Houston MS. Effect of a breastfeeding education and support program on breastfeeding initiation and duration in a culturally diverse group of adolescents. Journal of Nutrition Education 2000; 32(3): 139-45.

7 Protheroe L, Dyson L, Renfrew M, Bull J, Mulvahill C. The Effectiveness of Public Health Interventions to Promote the Initiation of Breastfeeding. NHS Health Development Agency Evidence Briefing. London: Health Development Agency, 2003.

8 World Health Organization (WHO). Protection, Promotion and Support of Breastfeeding in Europe: Review of Interventions. EU Project Contract No. SPC 2002359. Geneva: WHO, 2004

9 Swanson V, Power KG. A theoretically based, cross-cultural study of infant feeding in new mothers and their partners. 
In: Watson J, Platt S, eds. Researching Health Promotion. London: Routledge, 2000; 183-206.

10 Shepherd CK, Power KG, Carter H. Examining the correspondence of breastfeeding and bottle-feeding couples' infant feeding attitudes. Journal of Advanced Nursing 2000; 31(3): 651-60.

11 Kim Y. The effects of a breastfeeding campaign on adolescent Korean women. Paediatric Nursing 1998; 24(3): 235-40.

12 Goulet C, Lampron A, Marcil I, Ross L. Attitudes and subjective norms of male and female adolescents towards breastfeeding. Journal of Human Lactation 2003; 19(4): 402-10.

13 Littman H, Medendorp SV, Goldfarb J. The decision to breastfeed. The importance of fathers' approval. Clinical Pediatrics 1994; 33(4): 214-9

14 Kessler LA, Gielen AC, Diener-West M, Paige D. The effect of a woman's significant other on her breastfeeding decision. Journal of Human Lactation 1995; 11(2): 103-9.

15 Scott JA, Binns CW, Aroni RA. The influence of reported paternal attitudes on the decision to breastfeed. Journal of Paediatrics and Child Health 1997; 33(4): 305-7.

16 Arora S, McJunkin C, Wehrer J, Kuhn P. Major factors influencing breastfeeding rates: mothers' perception of father's attitude and milk supply. Paediatrics 2000; 106(5): $1-5$.

17 Ajzen I, Fishbein M. Understanding Attitudes and Predicting Social Behavior. Englewood Cliffs, NJ: Prentice-Hall, 1980.

18 Ajzen I. The theory of planned behaviour. Organizational Behavior and Human Decision Processes 1991; 50: 179-211.

19 Manstead ASR, Proffitt C, Smart JL. Predicting and understanding mothers' infant feeding intentions and behaviour: testing the theory of reasoned action. Journal of Personality and Social Psychology 1983; 44(4): 657-71.

20 O'Campo P, Faden R, Gielen A, Wang M. Prenatal factors associated with breast-feeding duration: recommendations for prenatal interventions. Birth 1992; 19(4): 195-201.

21 Janke JR. Development of the breast-feeding attrition prediction tool. Nursing Research 1994; 43(2): 100-4

22 Wambach KA. Breastfeeding intention and outcome: a test of the theory of planned behaviour. Research in Nursing $\varepsilon$ Health 1997; 20(1): 51-9.

23 Duckett L, Henly S, Avery M, Potter S, Hills-Bonczyk S, Hulden R, et al. A theory of planned behaviour-based structural model for breast-feeding. Nursing Research 1998; 47(6): 325-36.

24 Humphreys AS, Thompson NJ, Miner KR. Assessment of breastfeeding intention using the transtheoretical model and the theory of reasoned action. Health Education Research 1998; 13(3): 331-41.

25 Conner M, Armitage CJ. Extending the theory of planned behaviour: a review and avenues for further research. Journal of Applied Social Psychology 1998; 28(15): 1429-64.

26 Sheeran P, Orbell S. Augmenting the theory of planned behaviour; roles of anticipated regret and descriptive norms. Journal of Applied Social Psychology 1999; 29: 2107-42.

27 Trafimow D, Finlay K. The importance of subjective norms for a minority of people: between-subjects and withinsubjects analyses. Personality and Social Psychology Bulletin 1996; 22: 820-8.

28 Cialdini RB, Reno RR, Kallgren CA. A focus theory of normative conduct: recycling the concept of norms to reduce littering in public places. Journal of Personality and Social Psychology 1990; 58: 1015-26.

29 Fekadu Z, Kraft P. Expanding the theory of planned behaviour: the role of social norms and group identification. Journal of Health Psychology 2002; 7(1): 33-43.

30 Terry DJ, Hogg MA, White KA. The theory of planned behaviour: self-identity, social identity, and group norms. British Journal of Social Psychology 1999; 38(Pt 3): 225-44.

31 Povey R, Conner M, Sparks P, James R, Shepherd R. The theory of planned behaviour and healthy eating: examining additive and moderating effects of social influence variables. Psychology \& Health 2000; 14: 991-1006.

32 Wang QM, Fitzhugh EC, Westerfield RC, Eddy JM. Family and peer influences on smoking behaviour among American adolescents: an age trend. Journal of Adolescent Health 1995; 16(3): 200-3.

33 Rai AA, Stanton B, Wu Y, Li X, Galbraith J, Cottrell L, et al. Relative influences of perceived parental monitoring and perceived peer involvement on adolescent risk behaviours: an analysis of six cross-sectional data sets. Journal of Adolescent Health 2003; 33(2): 108-18.

34 Lau RR, Quadrel MJ, Hartman K. Development and change of young adults' preventive health beliefs and behaviour: influence from parents and peers. Journal of Health and Social Behavior 1990; 31(3): 240-59.

35 Gregg JEM. Attitudes of teenagers in Liverpool to breast feeding. British Medical Journal 1989; 299(6692): 147-8.

36 Greene J, Stewart-Knox B, Wright M. Feeding preferences and attitudes to breastfeeding and its promotion among teenagers in Northern Ireland. Journal of Human Lactation 2003; 19(1): 57-65.

37 Forrester IT, Wheelock G, Warren AP. Assessment of students' attitudes towards breastfeeding. Journal of Human Lactation 1997; 13(1): 33-7.

38 Dykes F, Griffiths H. Societal influences upon initiation and continuation of breastfeeding. British Journal of Midwifery 1998; 6(2): 76-8.

39 Cusson RM. Attitudes toward breast-feeding among female high-school students. Paediatric Nursing 1985; 11(3): 189-91.

40 McIntyre E, Hiller JE, Turnbull D. Attitudes towards infant feeding among adults in a low socio-economic community: what social support is there for breastfeeding? Breastfeeding Review 2000; 9(1): 13-24.

41 Campbell H, Jones I. Promoting breastfeeding: a view of the current position and a proposed agenda for action in Scotland. Journal of Public Health Medicine 1996; 18(4): 406-14.

42 Shepherd CK, Power KG, Carter H. Characteristics of responders and non-responders in an infant feeding study. Journal of Public Health Medicine 1998; 20(3): 273-9.

43 World Health Organization (WHO). Protecting, Promoting and Supporting Breastfeeding. Geneva: WHO, 1989.

44 Carstairs V, Morris R. Deprivation and Health in Scotland. Aberdeen: Aberdeen University Press, 1991.

45 Eagley AH, Chaiken S. The Psychology of Attitudes. Fort Worth, TX: Harcourt Brace Jovanovitch, 1983.

46 Conner M, Sparks P. The theory of planned behaviour and health behaviours. In: Conner M, Norman P, eds. Predicting Health Behaviour. Buckingham: Open University Press, 1999; 121-63.

47 Libbus MK. Perspectives of common breastfeeding situations: a known group comparison. Journal of Human Lactation 1992; 8(4): 199-203.

48 Aitken LS, West SG. Multiple Regression: Testing and Interpreting Interactions. Newbury Park, CA: Sage, 1991.

49 Earle M, Robson K. Analysis of Responses to the Consultation on the Breastfeeding (Scotland) Bill. Edinburgh: Scottish Parliament Information Centre, 2003.

50 Borsari B, Carey K. Descriptive and injunctive norms in college drinking: a meta-analytic integration. Journal of Studies on Alcobol 2003; 64(3): 331-41.

51 Sargent JD, Beach ML, Dalton MA, Mott LA, Tickle JJ, Ahrens $\mathrm{MB}$, et al. Effect of seeing tobacco use in films on trying smoking among adolescents: cross sectional study. British Medical Journal 2001; 323(7326): 1394-7.

52 Karvonen S, West P, Sweeting H, Rahkonen O, Young R. Lifestyle, social class and health related behaviour: a crosscultural comparison of 15 year olds in Glasgow and Helsinki. Journal of Youth Studies 2001; 4(4): 393-413. 